\title{
METALLURGICAL EVALUATION OF SPRAY DEPOSITED AND RING ROLLED IN718
}

\author{
Guoqing Zhang, Zhou Li, Shifan Tian, Hua Yuan, Ruiping Yao, Yifei Zhang, Yuxin Zhao, \\ Ling Guo and Minggao Yan \\ Beijing Institute of Aeronautical Materials (BIAM) \\ Beijing 100095, P.R.China
}

Keywords: IN 718, Spray forming, Ring Rolling, Metallurgy

\begin{abstract}
IN718 has been developed in China for applications as aero-engine disks, seals and rings during the last twenty years. Although wrought products of IN718 could meet the requirements of aeroengine components, they exhibited chemical segregation and large grain structure and were difficult-to-process. To overcome the problems encountered with the wrought alloy, a research program aims to develop a unique spray forming process to make sound ring performs and ring rolled parts. Trials were conducted to optimize the process parameters for producing high quality rings. This paper summarizes the results of metallurgical and mechanical evaluation for IN718 in the forms of as-sprayed, spray formed plus ring rolled preforms. Compared to the ingot metallurgy process for wrought products, the unique spray forming process utilized in the program was capable of producing ring preforms with remarkably reduced segregation, finer and more homogeneous microstructure, significantly improved hot workability, and comparable and improved mechanical properties. It was indicated from the evaluation that spray forming could also be utilized to process more highly alloyed and more difficult-to-process than the conventional wrought IN718, and even previously non-forgeable alloys.
\end{abstract}

\section{Introduction}

For the alloy IN 718, ingot metallurgy (IM) has been a conventional technology for making aeroengine components, such as turbine disks, rings and cases for aerospace applications. Compared to the powder metallurgy superalloys, the relatively low volume fraction of total strengthening phase and the sluggish precipitation reaction for $\gamma^{\prime \prime}$ make this possible. The melting process normally involves a combination of vacuum induction melting, electro slag refining and vacuum arc remelting. Billets are prepared for forging and ring rolling by an upsetting and drawing sequence of hot deformation. However, due to the relatively high volume fraction of niobium content in the alloy IN 718, large-size ingots encountered difficulties for the processing and fabrication and resulted in inhomogeneous chemistry, non-uniformity in microstructure, large grain size and low hot-workability.

As an integrated atomisation and deposition technique, which comprises the steps of providing a source of molten alloy, converting the melt into a spray droplets by gas atomisation, directing the droplets at a collector where they re-coalesce to form a high density, semi-finished preform, spray forming may offer the metallurgical advantages of rapid solidification techniques while avoiding the disadvantages incurred by the conventional wrought superalloys. For the last over ten years, considerable efforts have been directed toward developing spray forming technique as 
a cost-effective production technology and potential alternative to ingot metallurgy and powder metallurgy for the more compositionally complex superalloys for gas turbine applications [1-5].

The present research program aims to develop spray forming technology suitable for making sound superalloy preforms and to improve the mechanical properties and hot workability of compositionally complex and high performance superalloys. The metallurgical quality, microstructural development and mechanical properties of spray deposited ring preforms and ring rolled IN 718 products were evaluated in this paper.

\section{Materials and Experimental Procedure}

\section{$\underline{\text { Materials }}$}

The melt stocks of Alloy 718 were prepared using a vacuum induction melting furnace. The chemical compositions (wt.\%) of IN 718 as in specification, VIM heat and in spray ring preforms are listed in Table 1.

Table 1. Chemical composition (wt.\%) of IN 718

\begin{tabular}{|c|c|c|c|c|c|c|c|}
\hline Element & $\mathrm{Ni}$ & $\mathrm{Cr}$ & $\mathrm{Mo}$ & $\mathrm{Nb}$ & $\mathrm{Ti}$ & $\mathrm{Al}$ & $\mathrm{C}$ \\
\hline Specification & Bal & $\begin{array}{r}18.00- \\
21.00\end{array}$ & $\begin{array}{c}2.80- \\
3.30\end{array}$ & $\begin{array}{r}4.75- \\
5.50\end{array}$ & $\begin{array}{c}0.75- \\
1.15\end{array}$ & $\begin{array}{r}0.30- \\
0.70\end{array}$ & $\begin{array}{c}0.02- \\
0.08\end{array}$ \\
\hline VIM heat & Bal & 18.86 & 3.19 & 5.31 & 1.01 & 0.51 & 0.034 \\
\hline Spray ring & Bal & 18.56 & 3.14 & 5.26 & 1.00 & 0.52 & 0.042 \\
\hline
\end{tabular}

\section{$\underline{\text { Spray Forming System and Process }}$}

A spray forming research facility was designed and established at BIAM in the early and modified in the late 1990's to form a unique pilot spray forming plant [6-7]. This facility consists basically of a vacuum melting chamber and a low-pressure spray chamber. The vacuum melting chamber contains a melting crucible capable of accepting a $75 \mathrm{~kg}$ nickel-base superalloys, a 160 $\mathrm{kW}, 2500 \mathrm{~Hz}$ induction coil, a heated tundish positioned between the melting crucible and an atomizer, and thermocouples to measure the melt temperature.

The spray chamber contains deposition collector for making billets and a hydraulic controlled motion mechanism with capability of rotational and linear travel along the collector axis. The collector can also move in the direction transverse to the spray axis and be inclined and eccentrically positioned prior to and during an atomisation-deposition operation. The facility has the capability of producing ring performs using a heated rotating mandrel as shown in Figure 1. This spray-forming unit is equipped with an atomising gas control system, allowing the use of either argon or nitrogen as the atomising gas, an instrument to control and measure the gas flow and video systems to observe atomisation and deposition process. The spray forming facility is also capable of producing powder when the preform collector is removed from the spray chamber. 
Spray forming is a three-stage processing approach that involves atomization, droplet flight and deposition. The spray-forming unit at BIAM has been adjusted and modified to meet the requirements of this research program [8]. Numerous atomization processing variables, including gas type, melt superheat, gas/metal flow ratio and chamber pressure, were considered to study their effects on the porosity and microstructures of spray-deposited materials. The major processing variables used in this investigation are listed in Table 2.

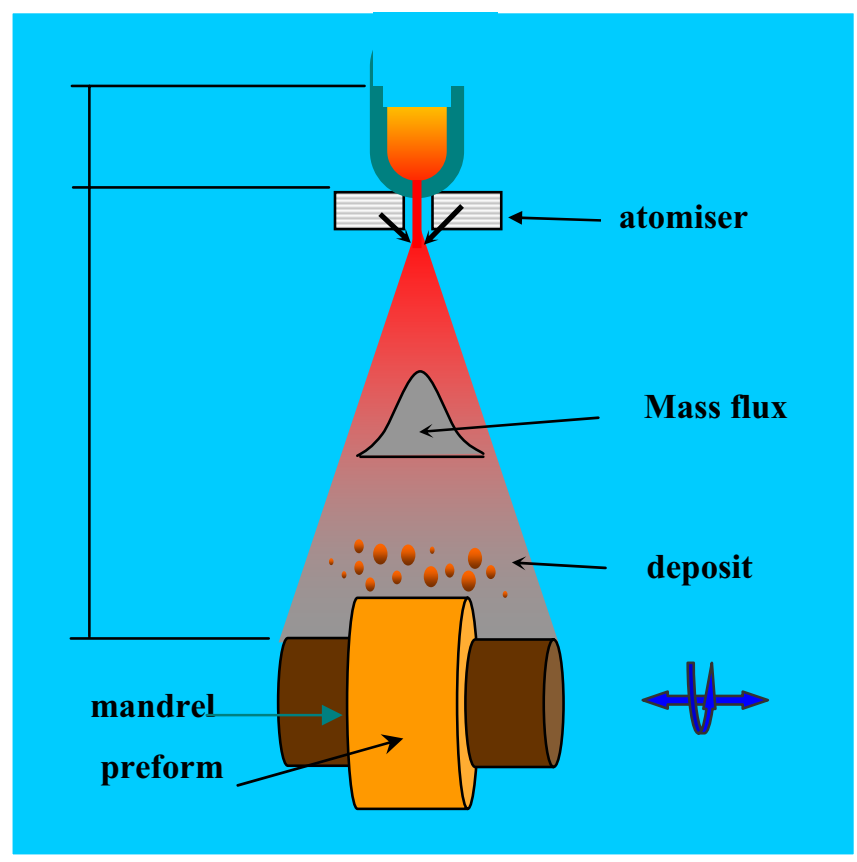

Figure 1. Schematic of spray forming process for ring preform

Table 2. Process parameters used in the SF experiments.

\begin{tabular}{|c|c|c|c|c|c|}
\hline $\begin{array}{c}\text { Atomizing } \\
\text { Gas }\end{array}$ & $\begin{array}{c}\text { Spray height } \\
(\mathrm{mm})\end{array}$ & $\begin{array}{c}\text { Chamber pressure } \\
(\mathrm{MPa})\end{array}$ & $\begin{array}{c}\text { Melt superheat } \\
\left({ }^{\circ} \mathrm{C}\right)\end{array}$ & $\begin{array}{c}\text { Melt pour rate } \\
(\mathrm{Kg} / \mathrm{min})\end{array}$ & $\begin{array}{c}\text { Atomizing pressure } \\
(\mathrm{MPa})\end{array}$ \\
\hline Nitrogen & $400-500$ & $0.03-0.1$ & $100-200$ & $10-20$ & $2.0-2.5$ \\
\hline
\end{tabular}

\section{Subsequent Thermal Processing}

Spray formed ring preforms were further consolidated by HIPping at $1150^{\circ} \mathrm{C}$ and $150 \mathrm{MPa}$ for 4 hours in argon to seal the porosity. HIPped rings were directly ring rolled at $950-1060^{\circ} \mathrm{C}$ to the designed sizes. The rolled rings were subsequently heat treated by normal solution followed by two-step ageing to optimize the mechanical properties. The heat treated rings were then sectioned to allow metallurgical investigation and mechanical testing.

\section{Results and Discussion}

The quality of spray formed preforms and ring rolled materials was evaluated in five ways: (1) oxygen and nitrogen contents, (2) grain size, (3) other microstructural features, (4) density (or porosity) and (5) mechanical properties.

Spray Formed Preform and Ring 
After the optimization of the spray atomization and deposition process, parameters were established to produce high-density (higher than 99\%) superalloy billets and rings. The most important process variables identified were chamber pressure, metal flow rates, atomizing gas pressure, spray distance, superheat and collector settings. Figure 2 shows a typical spray formed ring preform from the experimental trials. Spray formed and HIPped preforms were directly ring rolled to evaluate the workability of the spray formed "non-hot workable" materials. The spray formed superalloy exhibited excellent forgeability. Both qualitative and quantitative results obtained from ring roll operation indicated that the spray formed ring performs of superalloys were easier to ring roll, as compared to their wrought counterparts of the same alloys. The improved hot workablility of spray formed alloys was a result of the improved homogeneity and refined microstructure. An example of the rolled rings is shown in Figure 3.

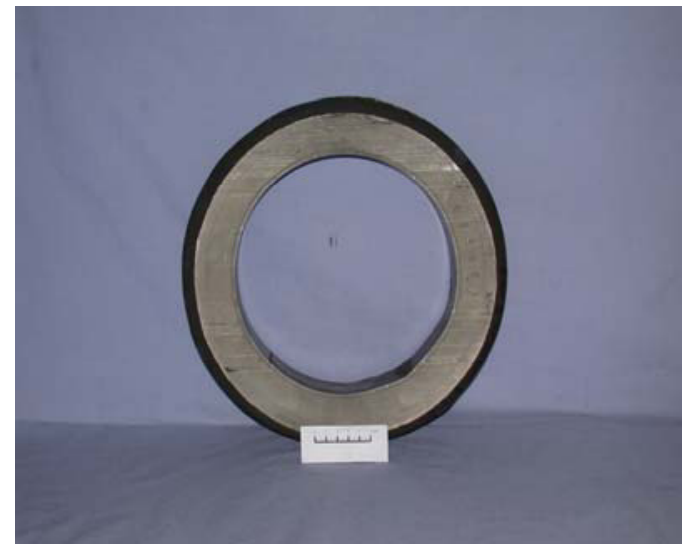

Figure 2. Spray formed ring preform of IN 718

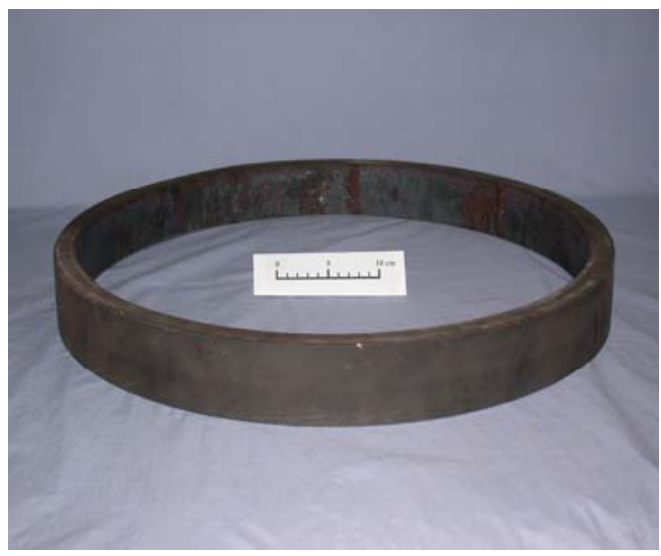

Figure 3. Spray formed ring rolled IN 718 ring shape

\section{$\underline{\text { Gas Content }}$}

As revealed in Table 3, there was very low pick up of the oxygen and hydrogen during spray forming with nitrogen atomisation. It is also evident that the nitrogen pickup was considerable with nitrogen atomisation. Since the solubility of nitrogen in nickel-base superalloys is low, nitrogen levels in excess of its saturation level would result in precipitation of TiN or more complex $(\mathrm{Ti}, \mathrm{Nb})(\mathrm{C}, \mathrm{N})$ both at grain boundaries and within the grains [3]. The revert was used as the melt stock for spray forming, thus the nitrogen content of spray formed 718 is relatively high.

Table 3. Nitrogen, oxygen and hydrogen contents in the spray formed disk alloy (wt. ppm). 


\begin{tabular}{|c|c|c|c|c|c|c|c|}
\hline Gas & $\mathrm{N}_{2}$ & $\mathrm{O}_{2}$ & $\mathrm{H}_{2}$ & Gas & $\mathrm{N}_{2}$ & $\mathrm{O}_{2}$ & $\mathrm{H}_{2}$ \\
\hline VIM melt stock & 10 & 14 & $<1$ & Preform & 510 & 16 & 1 \\
\hline
\end{tabular}

\section{Preform Density and Consolidation}

The density measurements for the spray formed preforms were obtained from the average measurements of the density samples taken from the sections of the preforms. After the optimisation of processing parameters, the porosity of the nitrogen-atomized preforms could be less than vol.1\% in every section of the preforms.

The residual porosity $(<1 \%)$ in the as-deposited preforms, which was isolated and not interconnected, was eliminated by HIP and a density in excess of $99.9 \%$ of theoretical density was achieved after HIP. The preforms were successfully consolidated to a density of almost $100 \%$ by using HIP and hot rolling.

\section{$\underline{\text { Microstructural Development }}$}

The typical microstructures of spray deposited and ring rolled materials are shown in Figure 4. The microstructure consisted of equiaxed structure with an average grain size ranging from ASTM 7 to 8, depending on the process conditions. Due to the rapid solidification during the spray atomisation, essentially no chemical segregation nor macro-segregation were evident. Additionally, no prior particle or splat boundaries were observed in the spray formed materials. The microstructure of the deposited material shown in SEM micrograph at higher magnification indicated a variety of precipitates (e.g. $\delta$ phase and carbides) formed during sequential steps of atomisation and deposition process (Figure 5).
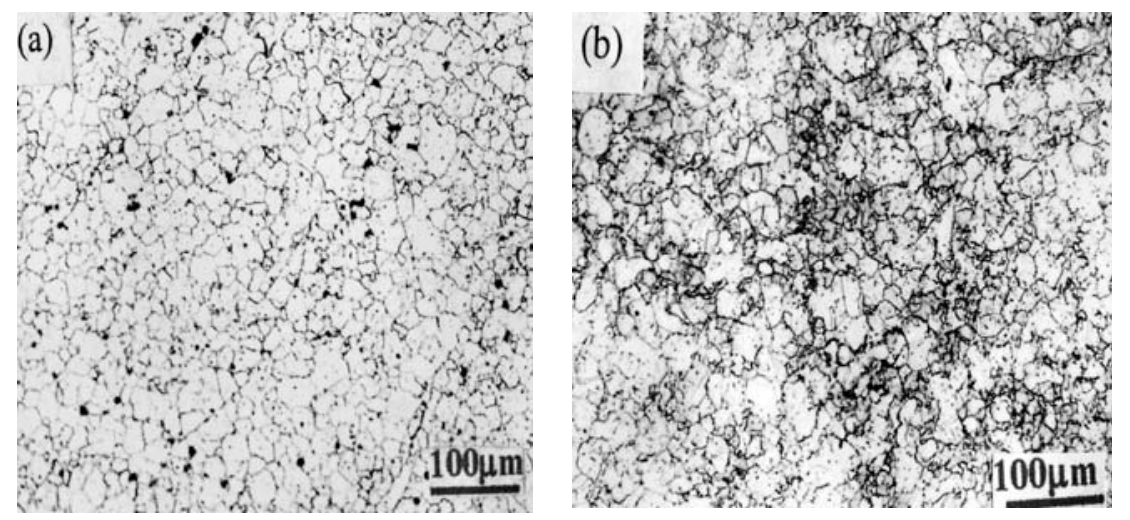

Figure 4. Optical microstructure of as-spray formed (a) and rolled (b) IN 718 ring
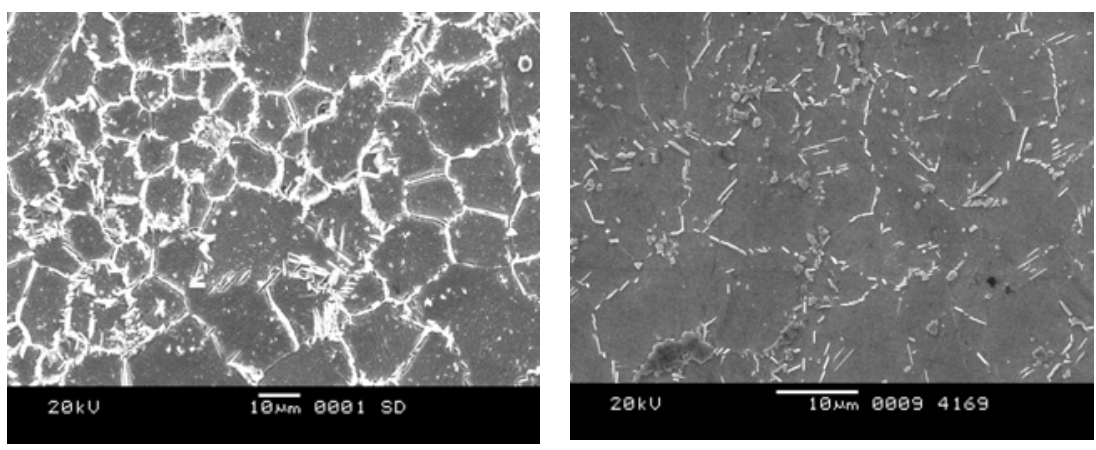
Microstructural observations revealed that HIP did not coarsen the grain size of spray formed materials. Hot rolling refined the grain size of spray formed materials from ASTM 7-8 to ASTM 9-10, as shown in Figure 6. A recrystallized, equiaxed and fine microstructure was obtained after the heat treatment. $\gamma^{\prime \prime}$ phase and $\gamma^{\prime}$ phase of two different sizes precipitated during the heat treatment (Figure 7).

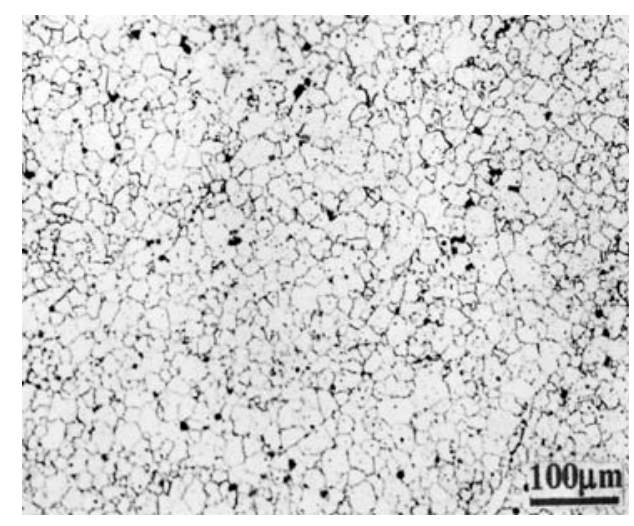

Figure 6. Optical microstructure of sprayed and rolled IN 718 ring after heat treatment
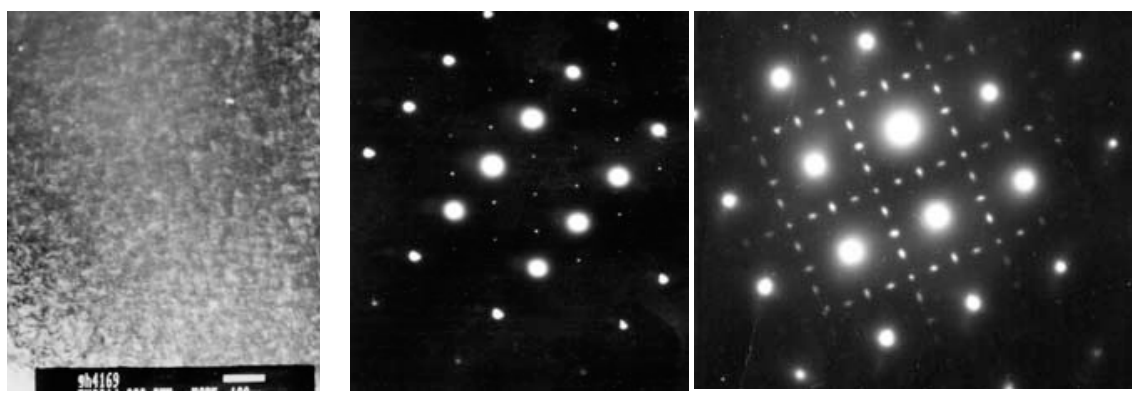

Figure 7. TEM microstructure of IN 718 ring showing $\gamma^{\prime}$ and $\gamma^{\prime \prime}$ and their diffraction patterns

\section{$\underline{\text { Mechanical Properties }}$}

Tensile properties of spray formed and hot processed materials after heat treatments were determined at room temperature and $650^{\circ} \mathrm{C}$. As listed in Table 4, the tensile properties of spray formed and rolled rings were significantly improved when compared to IM processed materials. The tensile properties of spray formed and rolled rings were also remarkably higher than those required in the specification for IN 718 ring materials. This may be explained by the unique microstructure developed by the spray forming, HIP and ring rolling process.

Table 4. Tensile properties of IN 718 rings

\begin{tabular}{|c|c|c|c|c|c|}
\hline Test temp. & Condition & $\begin{array}{c}0.2 \% Y S \\
(\mathrm{MPa})\end{array}$ & $\begin{array}{c}\text { UTS } \\
(\mathrm{MPa})\end{array}$ & $\begin{array}{c}\text { EL } \\
(\%)\end{array}$ & $\begin{array}{c}\text { RA } \\
(\%)\end{array}$ \\
\hline $20^{\circ} \mathrm{C}$ & SF ring & 1228 & 1446 & 18.6 & 31.7 \\
\hline $20^{\circ} \mathrm{C}$ & IM ring & 1181 & 1352 & 18.0 & 45.0 \\
\hline $20^{\circ} \mathrm{C}$ & Specification & 1035 & 1275 & 12 & 15 \\
\hline $650^{\circ} \mathrm{C}$ & SF ring & 1039 & 1190 & 22.0 & 36.6 \\
\hline
\end{tabular}




\begin{tabular}{|c|c|c|c|c|c|}
\hline $650^{\circ} \mathrm{C}$ & IM ring & 910 & 1070 & 16.8 & 33.0 \\
\hline $650^{\circ} \mathrm{C}$ & Specification & 862 & 1000 & 12 & 15 \\
\hline
\end{tabular}

As shown in Table 5, stress rupture properties of the spray formed superalloy at $650^{\circ} \mathrm{C}$ were comparable to the property levels of the wrought counterpart of the same alloy. Thermal processing consolidated the materials, improved the uniformity of the microstructure, and modified the distribution, precipitation of the $\delta, \gamma^{\prime \prime}$ and $\gamma^{\prime}$ phases, and thereby resulted in significant improvement on the stress rupture at $650^{\circ} \mathrm{C}$. Also, tensile and stress rupture properties of the spray formed and rolled IN 718 exhibited little directionality when tested in axial and radial directions.

Table 5. Stress rupture properties of IN 718 at $650^{\circ} \mathrm{C} / 690 \mathrm{MPa}$

\begin{tabular}{|c|c|c|c|c|}
\hline Condition & As-sprayed & Spray + rolled & IM rolled & Specification \\
\hline Life, hour & 165 & 235 & 42 & $\geq 25$ \\
\hline Elongation, $\%$ & & 18.5 & 11.6 & $\geq 5$ \\
\hline
\end{tabular}

\section{Conclusions}

Spray forming was demonstrated as a feasible approach to make high-density IN 718 ring preforms with little gas pick-ups using a unique pilot low-pressure spray forming plant. High density $(>99 \%)$ rings could be spray formed after the optimization of the spray atomization and deposition process using nitrogen as the atomization gas.

Spray deposited materials typically exhibited the microstructural features of rapidly solidified superalloys, i.e. unique fine and equiaxed grains, non-dendritic and homogeneous structure which result in significantly enhanced workability and improved mechanical properties compared to the conventional wrought products.

Ring preforms were successfully processed by HIP and ring rolling. The thermal-mechanical processing could consolidate the preforms and further refine the microstructure of the spray formed materials.

The evaluation indicates that spray forming could be utilized to process and develop more highly alloyed and more difficult-to-process than the conventional wrought IN718, and even previously non-forgeable alloys.

\section{Acknowledgements}

The work was funded by Chinese Government through research contract 413180402 and supported by the National Hi-tech. R\&D Program of China (No. 2002AA336100). The authors wish to thank our team members for technical assistant and helpful discussions.

\section{References}

1. R. H. Bricknell: Metall. Trans. A Vol. 17A (1986), p.583.

2. P. D. Prichard and R. P. Dalal: Superalloys 1992 (ed. R. D. Kissinger), (TMS, Warrendale, PA, USA 1996), p.205.

3. M. G. Benz et al.: Powder Metallurgy, Vol. 37 (1994), p.213. 
4. W. T.Carter et al.: Superalloys 718, 625, 706 and Various Derivatives (ed. E. A. Loria), (TMS, Warrendale, PA, USA 1997), p.27.

5. S. Tian et al.: Superalloys 1992 (ed. R. D. Kissinger), (TMS, Warrendale, PA, USA 1996), p.729.

6. G. Zhang et al.: The Third Pacific Rim International Conference on Advanced Materials and Processing (ed. M. A. Imam et al.), (TMS, Warrendale, PA, USA 1998), p.1687.

7. G. Zhang et al.: Proc. International Conference on Spray Deposition and Melt Atomisation (ed. K. Bauckhage et al.), (Bremen University 2000), p.161.

8. G. Zhang, Z. Li, Z. Liu, Z. Zhang, Y. Zhang, H. Yuan, R. Yao, S. Xu, S. Tian and M. Yan: Materials Science Forum, Vol. 475-479, 2004, 2773-2778. 